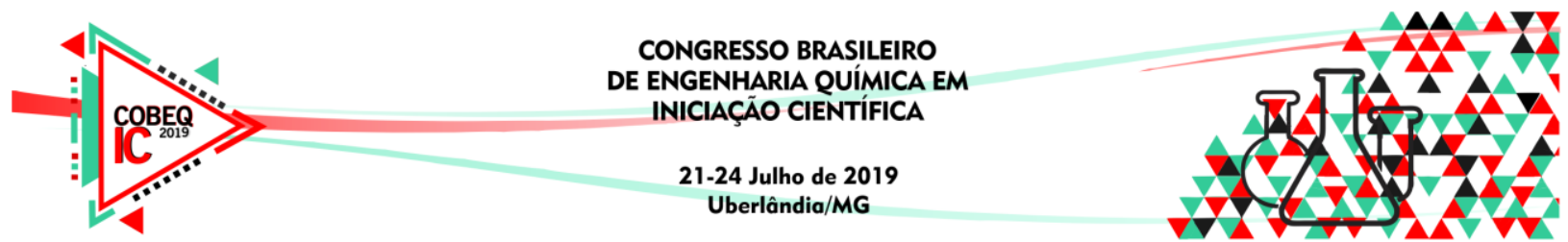

\title{
UTILIZAÇÃO DA VERMICULITA ORGANOFILIZADA COM SURFACTANTES CATIÔNICOS COMO POTENCIAL MATERIAL ADSORVENTE DE CONTAMINANTES EMERGENTES
}

\author{
L.V. S. FRANCISCO ${ }^{1}$, I. M. OLIVEIRA ${ }^{1}$, J. F. SILVA ${ }^{1}$, D.F. PEREIRA ${ }^{1}$ e V. D. CASTRO ${ }^{1}$ \\ Centro Universitário de Belo Horizonte, Faculdade de Engenharia Química \\ E-mail para contato: lucasvertelo@ hotmail.com
}

\begin{abstract}
RESUMO - A contaminação química da água cresce exponencialmente a cada ano. Tal ocorrência deve-se, em parte, ao descarte em cursos de água de compostos farmacêuticos, produtos de uso pessoal e hormônios, denominados contaminantes emergentes. A vermiculita é um mineral argiloso que, por apresentar propriedades como porosidade e elevados valores de área superficial específica, pode ser modificada tornando-se eficiente na adsorção de contaminantes emergentes. Tal modificação ocorre através do processo de organofilização, utilizando-se sais como o cloreto de alquil dimetil benzil amônio e o brometo de cetil trimetil amônio. Dessa forma, o objetivo do trabalho envolve testes de eficiência da vermiculita organofilizada com diferentes sais quaternários de amônio, relacionando sua capacidade adsorção em relação aos contaminantes. A comprovação do poder adsortivo da vermiculita organofilizada foi realizada através do teste de cinética de adsorção, a fim de definir o mecanismo correspondente. Observou-se alto potencial da vermiculita organofilizada por ambos sais quartenários de amônio na adsorção da cafeína.
\end{abstract}

\section{INTRODUÇÃO}

Atualmente, muito se discute sobre o cuidado com o meio ambiente, dando grande enfoque na preservação e tratamento de cursos de água. Segundo Soares e Leão (2015), no Brasil a água pode ser considerada de uso pessoal somente se atender aos requerimentos estabelecidos pela Portaria do Ministério da Saúde no 2.914/2011, porém tal portaria não contempla todos os parâmetros necessários para a fiscalização dos contaminantes emergentes presentes na água.

Soares e Leão (2015) e Grosseli (2016) afirmam que estão presentes em cursos de água fármacos como anti-inflamatórios, anticonvulsivos, antibióticos e estimulantes. Na classe dos hormônios, é possível citar o estrógeno, como por exemplo. Já na classe dos agrotóxicos estão presentes os inseticidas, herbicidas e fungicidas. Esses são alguns dos inúmeros contaminantes emergentes que estão presentes em nossos cursos de água e, não possuem tratamento adequado nas estações de tratamentos ao longo de todo o território nacional.

De acordo com Schaider et al. (2011), no que se refere ao cenário internacional, os contaminantes emergentes (denominados micropoluentes), também estão presentes na vida 


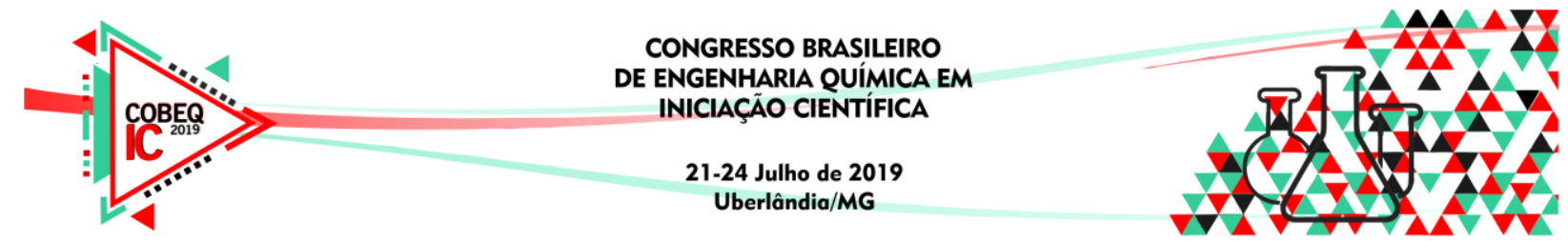

das pessoas, como confirma um estudo realizado em Cape Cod, Massachusetts - USA, em que análises apontaram presença desses compostos, como fármacos, hormônios, produtos químicos perfluorados e alquilfenóis. Muitos desses compostos foram encontrados em reservas de água potável e disponíveis para o consumo, parte deles são considerados nocivos à saúde, pois podem causar desregulação endócrina, podendo interferir no comportamento natural dos hormônios.

Segundo Ladeia, Souza e Freire (2015), a cafeína, um dos contaminantes emergentes de maior aparição em cursos de água, pode ser utilizada como indicador de outros contaminantes emergentes, visto que tal composto constitui a base para muitos subprodutos e que são excretados por vasta parte da população. Além disso, estudos de Altermann et al. (2008) mostraram que se pode enquadrar a cafeína na classe de contaminantes emergentes, pois seu consumo indireto em excesso pode gerar insônia, irritabilidade, ansiedade, náuseas e até desconfortos gastrintestinais.

Conforme Paiva et al. (2008), tendo em vista a iminente necessidade do controle daquelas substâncias, vê-se a utilização de argilominerais porosos como uma alternativa à remoção desses compostos presentes em cursos de água. A vermiculita modificada, por apresentar semelhança química com esses contaminantes e altos valores de área superficial específica, mostra-se promissora na adsorção dos micropoluentes. Tal modificação ocorre utilizando sais quaternários de amônio através do processo de organofilização, tornando-a seletiva a compostos orgânicos em decorrencia da troca catiônica.

Dessa forma objetiva-se a comprovação da eficiência de adsorção do argilomineral vermiculita organofilizada com diferentes sais quartenários e sua comparação, bem como a determinação do melhor tempo de adsorção e a quantidade máxima adsorvida para a cafeína.

\section{ORGANOFILIZAÇÃO}

O trabalho de Fernandes e Martendal (2015) afirma que a organofilização consiste em uma troca catiônica entre o íon presente na estrutura interna com o cátion orgânico presente nos sais quaternários de amônio que são utilizados no processo, geralmente, entre as lamelas do argilomineral é encontrado o cátion $\mathrm{Na}+$, que por sua vez possui facilidade troca.

Ainda conforme Fernandes e Martendal (2015), após o processo de tratamento orgânico na vermiculita, esta se encontra seletiva a compostos orgânicos, o que permite uma maior adsorção das substâncias que possuem esse caráter.

De acordo com Patrício et al. (2018) para que a organofilização ocorra, é necessário utilizar surfactantes catiônicos, os também chamados sais quaternários de amônio, eles são constituídos por cerca de dois grupos de hidrocarbonetos de cadeia longa e, possuem ligação direta a um átomo de nitrogênio na maioria das vezes, onde também se encontra a parte catiônica da molécula.

No presente estudo, foram utilizados dois sais quaternários de amônio, sendo eles o brometo de cetil trimetil amônio e o cloreto de alquil dimetil benzil amônio. 


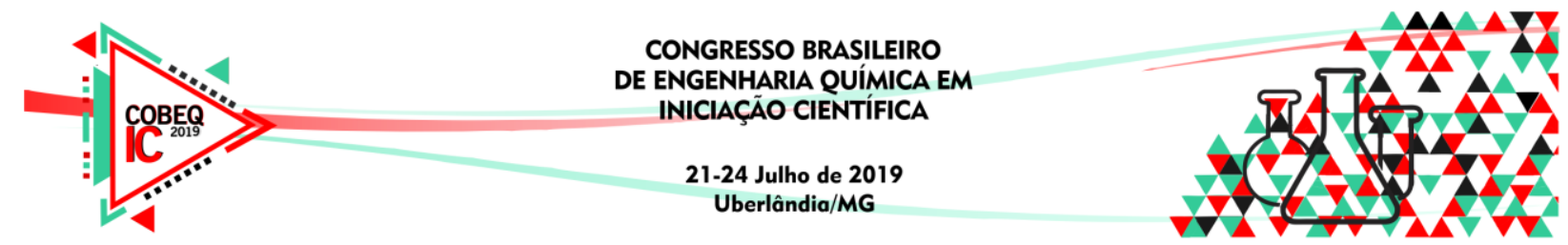

\section{METODOLOGIA}

A realização do processo de tratamento da argila foi dividida em duas partes, sendo a primeira a seleção granulométrica e purificação das impurezas da argila, e a segunda parte o processo de organofilização.

Para a seleção granulométrica, a argila in natura foi submetida ao processo de separação granulométrica e, para isto utilizaram-se peneiras Serie Tyler. Após o peneiramento, separouse a vemiculita de diâmetro médio de $2,0 \mathrm{~mm}$ para que fosse realizado o processo de limpeza da mesma.

Após separada, a vermiculita foi submetida ao processo de purificação, aplicou-se lavagem por água corrente e sob agitação manual, lavou-se até que a agua de refugo apresentasse coloração cristalina. Em sequência, levou-se a vermiculita para secagem em estufa a temperatura de $100^{\circ} \mathrm{C}$ por um período de $24 \mathrm{~h}$.

Segundo Paiva et al. (2008), para o processo de organofilização devem-se utilizar duas metodologias distintas, visto que há diferença entre os estados físicos dos sais, como descritas abaixo.

\subsection{Brometo de Cetil Trimetil Amônio}

Em um béquer foram adicionados $250,0 \mathrm{~mL}$ de água destilada com controle de temperatura e agitação mecânica. Após atingir a temperatura de $80 \pm 5,0{ }^{\circ} \mathrm{C}$ adicionaram-se $5,0 \mathrm{~g}$ de vermiculita já lavada e $1,53 \mathrm{~g}$ de brometo de cetil timetil amônio. As condições de temperatura e agitação mecânica foram mantidas por 20 min.

Atingido o tempo estipulado, retirou-se o sistema da agitação e aquecimento, lacrou-o e deixou-se em repouso por $24 \mathrm{~h}$. Em sequência, realizou-se a filtração a vácuo, utilizando papel filtro de faixa preta, despendendo cerca de $2000 \mathrm{~mL}$ de água destilada. A vermiculita organofilizada passou pelo processo de secagem em estufa, durante $24 \mathrm{~h}$ à temperatura de $60^{\circ} \mathrm{C}$.

\subsection{Cloreto de Alquil Dimetil Benzil Amônio}

Diluíram-se 1,67 g do cloreto de alquil dimetil benzil em $20 \mathrm{~mL}$ de água destilada e reservou-o. Em um béquer, adicionou-se os $120 \mathrm{~mL}$ de água destilada sob agitação mecânica, concomitantemente a isto, adicionou-se a argila e o sal diluído aos poucos na dispersão, mantendo o sistema sob agitação por cerca de 20 min.

Em seguida, retirou-se o sistema da agitação, lacrou-o e o deixou em repouso por $24 \mathrm{~h}$. Após esse período o material foi filtrado a vácuo utilizando-se papel filtro faixa preta, utilizando cerca de $2000 \mathrm{~mL}$ de água destilada. Feito isso, secou-se em estufa a argila organofilizada em temperatura de $60^{\circ} \mathrm{C}$ por um período de $24 \mathrm{~h}$. 


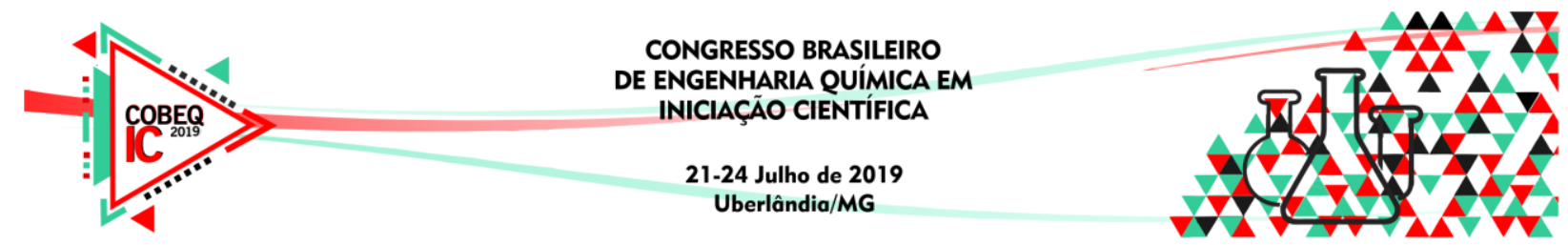

\subsection{Teste de adsorção}

Primeiramente criou-se a curva de calibração, utilizando-se o software UV Basic V1.40.0, e o espectrofotômetro UV/visível, de marca Global Trade Technology, modelo UV5100 , com comprimento de onda $273 \mathrm{~nm}$.

Pesou-se $0,10 \mathrm{~g}$ de vermiculita organofilizada, adicionou-se 50,0 $\mathrm{mL}$ de uma solução de cafeína e água destilada com concentração de $20,0 \mathrm{mg} . \mathrm{L}^{-1}$. Repetiu-se esse procedimento para os 2 sais.

As amostras foram submetidas à agitação mecânica em uma incubadora refrigerada com agitação de marca TECNAL TE - 424 (shaker), realizando-se leituras sobre a curva de calibração de 5 em 5 min e em triplicata, tal procedimento permitiu a quantificação da adsorção de cafeína pelo argilomineral tratado.

\section{RESULTADOS E DISCUSSÕES}

A partir dos resultados obtidos no teste de cinética, foi possível obter o comportamento de $\mathrm{q}\left(\mathrm{mg}_{\mathrm{g}} \mathrm{g}^{-1}\right)$ em função do tempo (min) e, notou-se que o sal cloreto de alquil dimetil benzil amônio apresentou maior eficiência na adsorção de cafeína, além disso demonstrou maior estabilidade de adsorção ao longo do tempo em relação ao brometo de cetil trimetil amômio, como pode ser comprovado pela figura 1 .

Figura 1 - Teste de cinética das amostras organofilizadas com os dois sais.

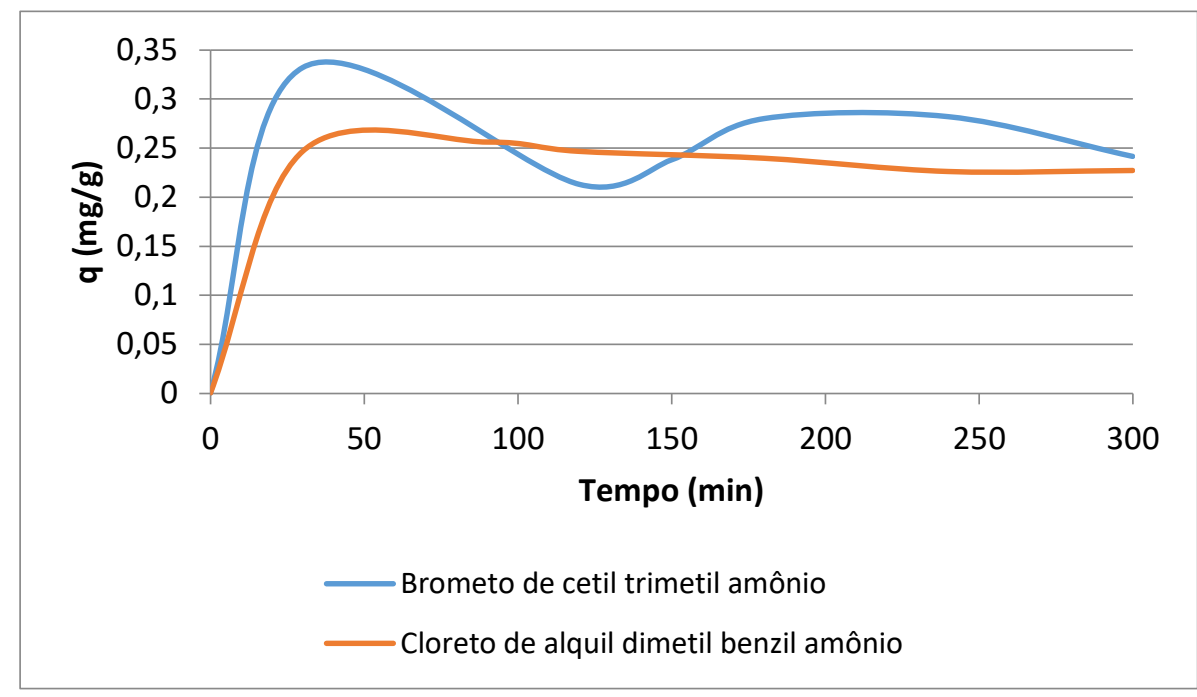

A partir disso, foram traçados gráficos para determinar a adequação aos modelos cinéticos já conhecidos de pseudoprimeira ordem e pseudosegunda ordem, afim de determinar a ordem de reação dos dois sais e consequentemente o tipo de mecanismo presente no processo de adsorção, analisado com base a linearidade dos dois modelos como observado nas Tabela 1. 


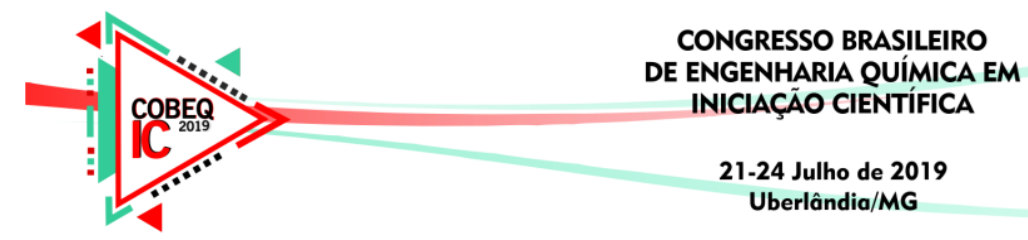

Tabela 1 - Comparação do teste cinético com os modelos de pseudoprimeira ordem e pseudosegunda ordem dos sais utilizados.

\begin{tabular}{|c|c|c|c|c|}
\cline { 2 - 5 } \multicolumn{1}{c|}{} & \multicolumn{2}{c|}{ Pseudoprimeira ordem } & \multicolumn{2}{c|}{ Pseudosegunda ordem } \\
\cline { 2 - 5 } \multicolumn{1}{c|}{} & Equação & $\mathrm{R}^{2}$ & Equação & $\mathrm{R}^{2}$ \\
\hline $\begin{array}{c}\text { Brometo de Cetil Trimetil } \\
\text { Amônio }\end{array}$ & $\mathrm{y}=-0,0079 \mathrm{x}-0,836$ & 0,621 & $\mathrm{y}=3,9205 \mathrm{x}+3,5445$ & 0,961 \\
\hline $\begin{array}{c}\text { Cloreto de Alquil Dimetil } \\
\text { Benzil Amônio }\end{array}$ & $\begin{array}{c}\mathrm{y}=-0,0048 \mathrm{x}- \\
2,4537\end{array}$ & 0,089 & $\mathrm{y}=4,5202 \mathrm{x}-40,701$ & 0,998 \\
\hline
\end{tabular}

Pôde-se comprovar uma maior adequação dos dois sais ao modelo cinético de pseudosegunda ordem, devido sua maior linearização quando comparado ao $\mathrm{R}^{2}$ (mais próximo de 1), conforme observado na Figura 2. Sendo que, de acordo com Nascimento et al. (2014), a adsorção global é o quadrado da força motriz, caracterizada por um processo de quimiossorção em monocamada e que a diferença entre a concentração da fase sólida em qualquer tempo é a força motriz da adsorção.

Figura 2 - Comparação dos sais relacionada ao modelo cinético de pseudosegunda ordem.

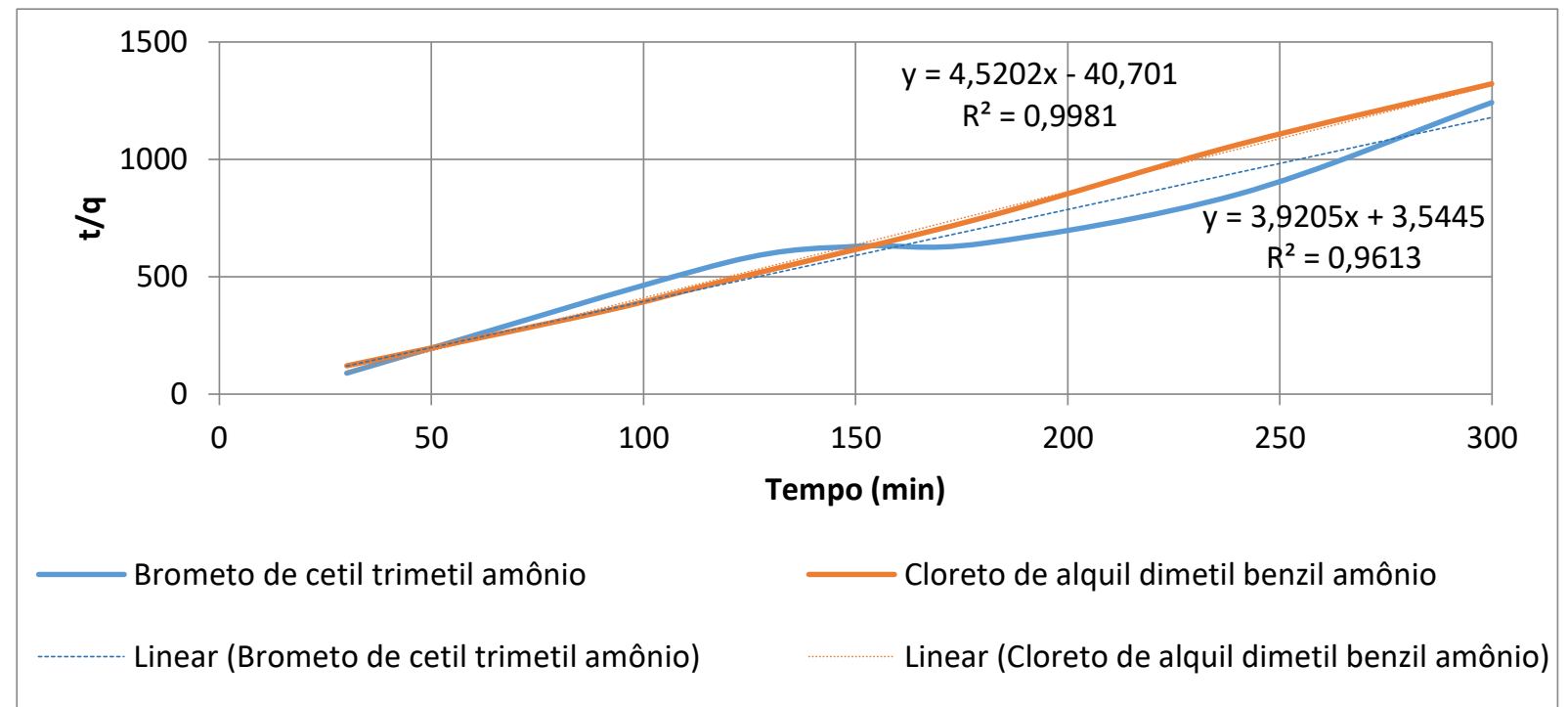

A partir do estudo da figura 2 acima, observou-se que o sal cloreto de alquil dimetil benzil amônio obteve maior adequação do modelo de pseudosegunda ordem e, consequentemente maior eficácia de adsorção. Uma das possíveis inferências sobre a melhor capacidade de adsorção do sal, é a sua maior estabilidade em relação ao sal brometo de cetil trimetil amônio, como pode ser observado nas figuras 1 e 2 . 


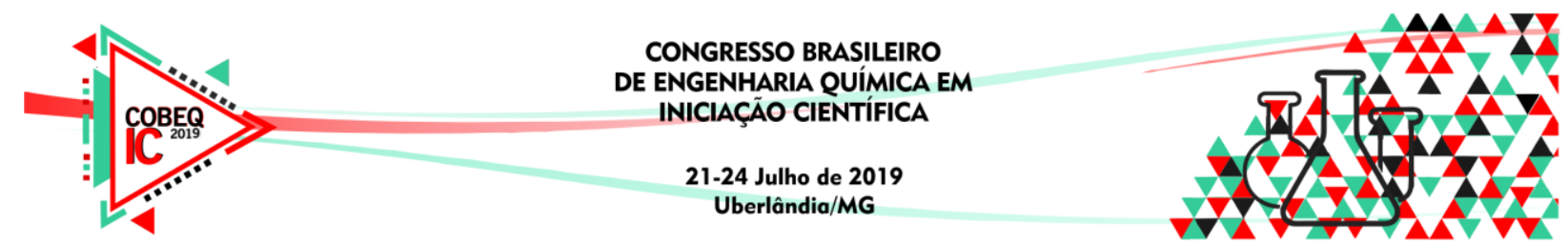

\section{CONCLUSÃO}

Pôde-se observar a eficiência da vermiculita organofilizada como adosrvente da cafeína em ambos os sais quartenários de amônio utilizados. Entretanto, houve uma maior linearização com o modelo cinético de pseudosegunda ordem utilizando o cloreto de alquil dimetil benzil amônio, demonstrando que o adsorbato ocupa o adsorvente por dois sítios ativos, sem competitividade entre as moléculas. Dessa forma, o material demonstra potencial para remoção de contaminantes emergentes.

\section{NOMENCLATURA}

q: capacidade de adsorção (mg.g $\left.{ }^{-1}\right)$; t: tempo (minutos).

\section{REFERÊNCIAS BIBLIOGRÁFICAS}

ALTERMANN, A. M; DIAS, C. S; LUIZ, M. V; NAVARRO, F. A influência da cafeína como recurso ergogênico no exercício físico: sua ação e efeitos colaterais. Revista Brasileira de Nutrição Esportiva, v. 2, p. 225-239, 2008.

FERNANDES, V. K; MARTENDAL, C. P. Superplásticos com nanopartículas de argila. 2015.

GROSSELI, G. M. Contaminantes emergentes em estações de tratamento de esgoto aeróbia e anaeróbia. Dissertação doutorado em ciências - Centro de ciências exatas e de tecnologia, Universidade Federal de São Carlos, 2016.

LADEIA, W. A; SOUZA, L. F. C. B; FREIRE, R. L. Cafeína em amostras de água de captação e tratada: um indicador químico de contaminação antrópica. Encontro anual de iniciação científica, XXIV, v. 24, p. 1-4, 2015.

PAIVA, L. B; MORALES, A. R.; DÍAZ, F. R. V. Argilas organofílicas: características, metodologias de preparação, compostos de intercalação e técnicas de caracterização. Cerâmica, v. 54, p. 213-226, 2008.

PATRÍCIO, A. C. L; SILVA, M. M; MOTA, M. F; LIMA, W. S; RODRIGUES, M. G. F. Processo de obtenção de argila organofilica utilizando dois sais quaternários de amônio (Praepagen e Dodigen). IV CNNQ/II ENNEQ, 2011.

SCHAIDER, L.; ACKERMAN, J; RUDEL, R; DUNAGAN, S; BRODY, J. Emerging Contaminants in Cape Cod Private Drinking Water Wells. Reserching the environment and women's health. Silent Spring Institute, 2011.

SOARES, A. F. S; LEÃO, M. M. D. Contaminação dos mananciais por micropoluentes e a precária remoção desses contaminantes nos tratamentos convencionais de água para potabilização. De Jure, Minas Gerais, v. 14, p. 38-87, 2015.

UGARTE, J. F. O; SAMPAIO, J. A; FRANÇA, S. C. A. Vermiculita. Rochas e Minerais Industriais, p.865-887, 2008. 